\title{
Implications of Low-grade Inflammation in SARS-CoV-2 Immunopathology
}

\author{
Anamary Suárez-Reyes MD and Carlos A. Villegas-Valverde MD MS
}

\begin{abstract}
INTRODUCTION Advanced age and chronic disease comorbidities are indicators of poor prognosis in COVID-19 clinical progression. Fatal outcomes in patients with these characteristics are due to a dysfunctional immune response. Understanding COVID-19's immunopathogenesis helps in designing strategies to prevent and mitigate complications during treatment.
\end{abstract}

OBJECTIVE Describe the main immunopathogenic alterations of COVID-19 in patients of advanced age or with chronic non-communicable diseases.

DATA ACQUISITION We carried out a bibliographic search of primary references in PubMed, Elsevier, Science Direct and SciELO. A total of 270 articles met our initial search criteria. Duplicate articles or those unrelated to at least one chronic comorbidity, senescence or inflammation and those that studied only patient clinical characteristics, laboratory tests or treatments were excluded. Finally, our selection included 124 articles for analysis: 10 meta-analyses, 24 original research articles, 67 review articles, 9 editorials, 9 comments, 3 books and 2 websites.

DEVELOPMENT Hypertension and diabetes mellitus are the most common comorbidities in COVID-19 patients. Risk of developing severe manifestations of the disease, including death, is increased in

\section{INTRODUCTION}

COVID-19 is caused by the SARS-CoV-2 virus,[1,2] the seventh member of the Coronaviridae family capable of infecting humans. [3-6] SARS-CoV-2 genomic modifications affect its pathogenicity, $[7,8]$ which, together with human genetic polymorphisms,[8-10] influence an individual's immune response and susceptibility to the virus.[7-12] Clinical presentations are varied and can affect all systems in the body.[13-15] Worse prognosis is experienced by those aged $\geq 60$ years and those with pre-existing comorbidities.[15-18] Mortality in this age group is especially associated with immunosenescence and the presence of such chronic noncommunicable diseases,[19] both of which can increase risk of complications.[13]

Approximately $80 \%$ of COVID-19 deaths occur in those aged $\geq 65$ years.[20] These patients are more likely to develop dysfunctional immune response, accompanied by changes in the lung microenvironment, in barrier immunity, macrophage and dendritic cell

\section{IMPORTANCE}

Comorbidities, age and immunological factors are key in COVID-19 clinical evolution. This review provides an update on immunological factors that influence COVID-19 severity and lethality in older adults and chronic disease patients. senescent and obese patients and those with cardiovascular disease, cancer or chronic obstructive pulmonary disease. Low-grade chronic inflammation is characteristic of all these conditions, reflected in a proinflammatory state, endothelial dysfunction, and changes to innate immunity; mainly of the monocyte-macrophage system with changes in polarization, inflammation, cytotoxicity and altered antigenic presentation. In the case of SARS-CoV-2 infection, mechanisms involved in acute inflammation overlap with the patient's pro-inflammatory state, causing immune system dysfunction. SARS-CoV-2 infection amplifies already-existing alterations, causing failures in the immune system's control mechanisms. The resulting cytokine storm causes an uncontrolled systemic inflammatory response marked by high serum levels of inflammatory biomarkers and a pro-inflammatory cytokine profile with decompensation of underlying diseases. In asthma, chronic eosinophilic inflammation protects against infection by producing a reduced interferon-mediated response and a reduced number of ACE2 receptors.

CONCLUSIONS Low-grade chronic inflammation present in advanced age and chronic diseases_-but not in bronchial asthma — produces a pro-inflammatory state that triggers a dysregulated immune response, favoring development of severe forms of COVID-19 and increasing lethality.

KEYWORDS SARS-CoV-2, COVID-19, inflammation, aging, chronic disease, immune system

maturation and migration and T-lymphocyte activation, causing immune system dysregulation.[21]

We live in an aging world in which 1 in 11 people are aged $\geq 65$ years,[22] while chronic non-communicable diseases (NCDs) cause $71 \%$ of global deaths. Cardiovascular disease, cancer, respiratory disease and diabetes are responsible for $>80 \%$ of premature death from NCDs.[23] In Cuba, $20.8 \%$ of the population is aged $\geq 60$ years, and the NCD mortality rate is the highest among all causes of death at 791.9 deaths per 100,000 population. In this age group, the prevalence rates of hypertension (759.2 and 508.1 per 1000 population in age groups 60-64 years and $\geq 65$ years, respectively) and diabetes mellitus (250.9 and 165.6 per 1000 population in age groups $60-64$ years and $\geq 65$ years, respectively) are higher than in other age groups. Asthma has a higher prevalence during adolescence, although in 2019, a rate of 145.9 per 1000 population was reported in patients aged 60-64 years. The incidence of cancer in people aged $\geq 60$ years has increased considerably in the last decade (1910.9 and 1275.3 per 100,000 population for men and women respectively, in 2019).[24]

Due to the worldwide increase in life expectancy, as well as the high NCD prevalence, the pandemic must be faced with a syndemic approach.[25] Studying changes in immune system response helps to better understand the lethality of the disease and improve interventions targeting the modifiable risk factors that can contribute to fatal outcomes and complications, mainly in older adults. 
The objective of this review is to describe the main immunopathogenic alterations to COVID-19 progression related to low-grade inflammation in older adults and patients with chronic non-communicable diseases.

\section{DATA ACQUISITION}

We carried out a bibliographic review of the PubMed, Elsevier, Science Direct and SciELO databases in Spanish and English. We used three search strategies consisting of a combination of descriptors with Boolean operators; a restricted form "AND" for non-homologous terms and an additive form "OR" for homologues:

- "COVID-19" OR "SARS-Cov-2" AND "low-grade inflammation" OR "chronic inflammation"

- "COVID-19" OR "SARS-CoV-2" AND "hypertension" OR "diabetes mellitus" OR "obesity" OR "cancer" OR "asthma" OR "chronic obstructive pulmonary disease"

- "hypertension" OR "diabetes mellitus" OR "obesity" OR "cancer" OR "asthma" OR "chronic obstructive pulmonary disease" AND "low-grade inflammation".

Articles related to COVID-19 were reviewed if published in 2020; articles related to other topics were restricted to the period 20002020. Articles published prior to those dates that were cited in the originally selected articles were also included. Demographic and morbidity data were obtained from the official websites of the UN,[22] WHO[23] and the National Health Statistics Yearbook of the Cuban Ministry of Public Health (MINSAP).[24]

Initially, 270 articles met the search criteria. Duplicate articles or articles unrelated to at least one chronic comorbidity, senescence or inflammation and those that studied only patient clinical characteristics, laboratory tests or treatments were excluded (Figure 1). Our final selection included 124 articles: 10 meta-analyses, 24

\section{Figure 1: Literature review process}

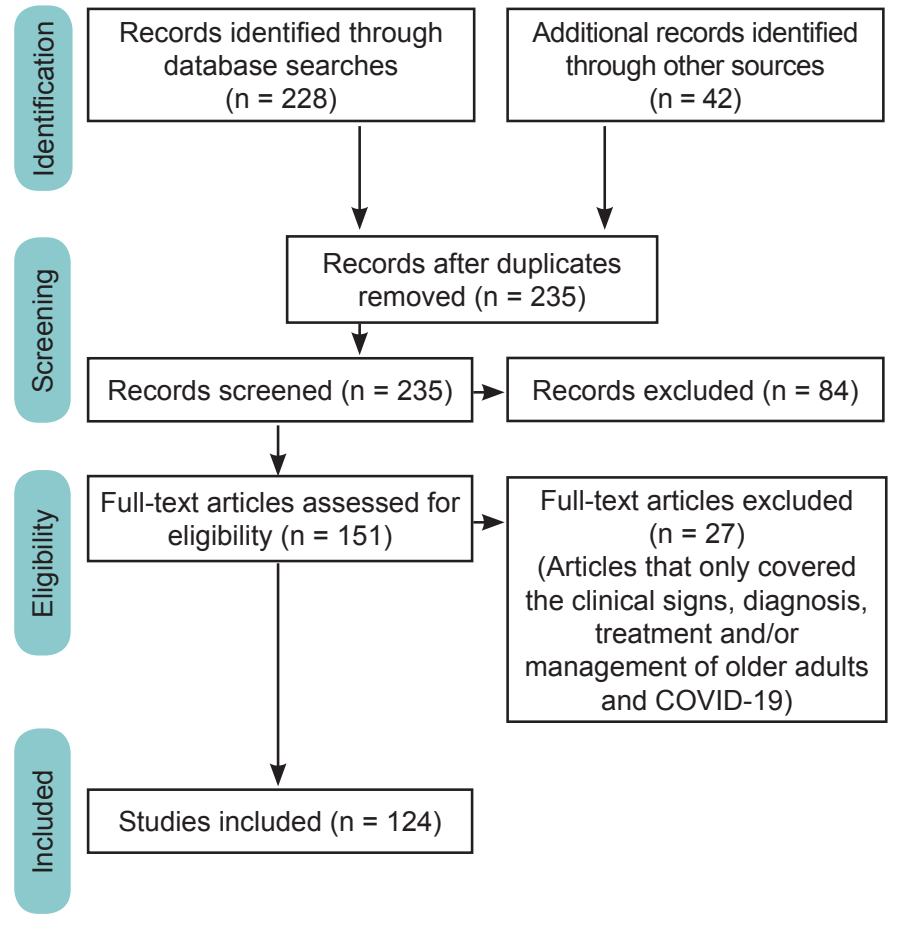

original research articles, 67 review articles, 9 editorials, 9 comments, 3 books and 2 websites. Preprints were not included in the search.

\section{DEVELOPMENT}

Immune system involvement in COVID-19 SARS-CoV-2infected patients can develop different clinical presentations of COVID-19, and are more likely to die if they have pre-existing comorbidities or are aged $\geq 60$ years.[26] A functional immune system is needed to combat infection and maintain a state of homeostasis; when immune system function is disturbed, the breakdown of this equilibrium can lead to fatal outcomes.[27,28]

The first line of defense in SARS-CoV-2 infection is the innate immune response.[29] The type, quality and efficacy of this response determine the adaptive immune response and influence the course of infection.[30] A failed immune response to severe acute respiratory syndrome is described as being 'trapped' in innate immunity, while progression to adaptive immunity if associated with more favorable outcomes.[31]

Lung injury in COVID-19 patients occurs either directly, due to destruction of epithelial cells and alterations in the alveolar and bronchial macrophages, or indirectly, through activation of inflammatory mediators released by invariant $\mathrm{T}$ lymphocytes associated with respiratory mucosa and Tүס lymphocytes.[32,33]

COVID-19 patients have larger atypical vacuolated monocytes than normally seen in healthy individuals. Additionally, they present with a decrease of $95.1 \%-78.7 \%$ in the number of classic monocytes in circulation, with an increase of $0.49 \%-4.34 \%$ in the number of intermediate monocytes and a $4.4 \%-17.0 \%$ increase of non-classic monocytes compared to healthy individuals.[34] Both monocytes and macrophages can be infected by SARSCoV-2, which elicits inflammatory responses and changes in gene expression related to the immune system in cells infected with SARS-COV-2.[32] Even in the absence of symptomatic infection, monocytes and macrophages can cause viral shedding in the host outside the respiratory system.[35] In COVID-19, Th1 lymphocytes respond by secreting the proinflammatory cytokines IL-6, interferon gamma (IFNY), interferon gamma-induced protein 10 (IP-10) and monocyte chemoattractant protein-1 (MCP1), which attract monocytes and $\mathrm{T}$ lymphocytes to the infected site, resulting in lymphocytopenia and an increase in the neutrophillymphocyte ratio (Figure 2).[36]

Pericyte and endothelial cell dysfunction from direct infection or inflammation affects microcirculation.[37] Dysregulated immune responses are involved in thrombosis and endothelial dysfunction,[38] and promote acute inflammation and hypercoagulation, both of which are exacerbated by cytokine storms.[38,39] Increased endothelial dysfunction is also associated with a decrease in physical exercise and an abrupt increase in body weight, both products of social isolation, and both of which cause oxidative stress.[40] Endothelial changes resulting from low-grade inflammation during COVID-19 are considered by some authors to be an epiphenomenon.[38]

Decreased monocyte expression of HLA-DR molecules interferes with the adaptive immune response during acute infection and is associated with progression to severe respiratory failure. [31] An increase in IL-6-producing TCD4+ lymphocytes has been 
Figure 2: Implications of low-grade chronic inflammation in seriously ill or deceased SARS-CoV-2 patients

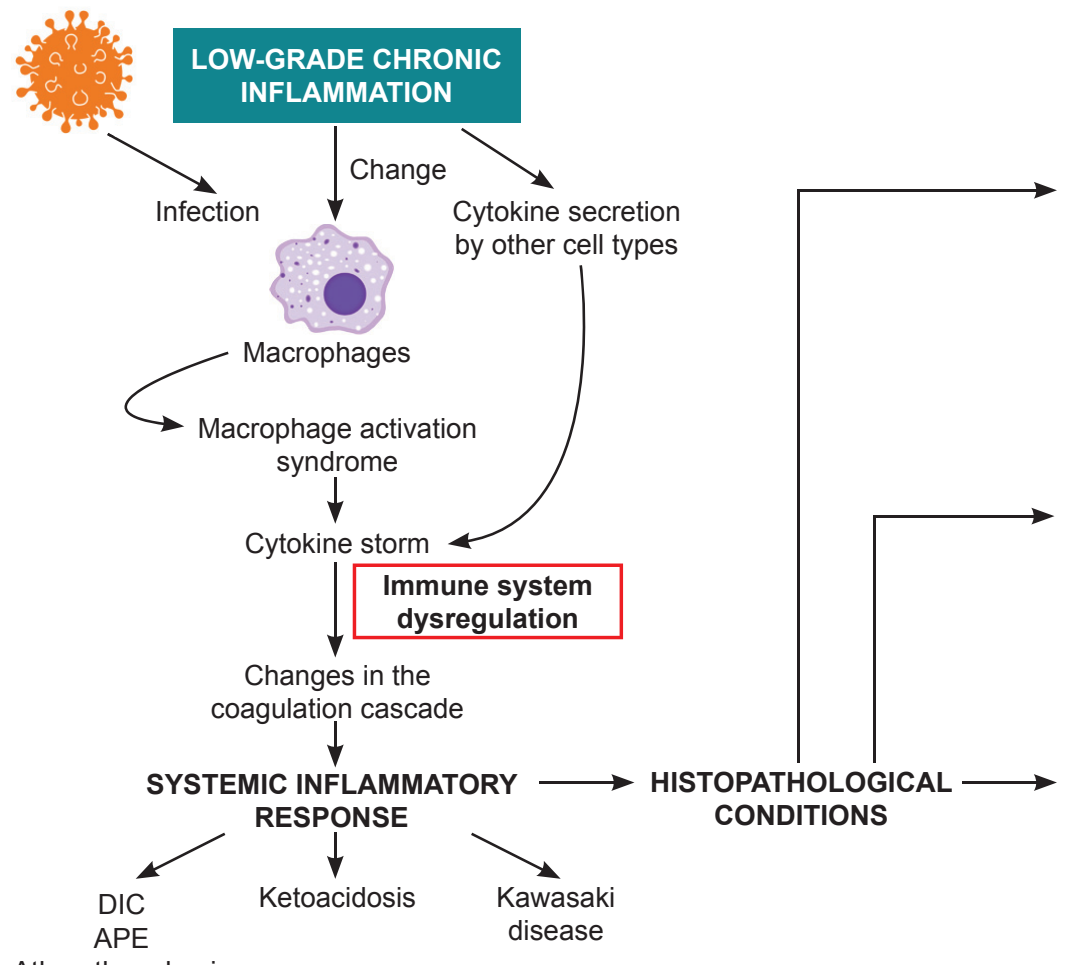

\section{RESPIRATORY SYSTEM}

- Bronchi and bronchial blockage by mucus plugs

- Bronchial epithelial cell damage

- Marked proliferation of type II alveolar epithelial cells

- Lymphocyte and mononuclear cell infiltration into alveolar septal spaces

- Prominent polynuclear giant cells

- Fibrinous exudate and hyaline membranes filling alveolar cavities

\section{IMMUNE SYSTEM}

- Splenic atrophy

- Splenic necrosis and hemorrhage

- Significant reduction in neutrophils, TCD4+ and TCD8+

- Lymphocyte depletion

\section{CARDIOVASCULAR SYSTEM}

- Myocardial injury

- Cardiomyopathy

- Fulminant heart failure

- Acute coronary syndrome

- Cardiogenic shock

Atherothrombosis

DIC: disseminated intravascular coagulation APE: acute pulmonary embolism.

described, with an accompanying decrease in regulatory $\mathrm{T}$ lymphocytes (Treg) and Ty $\delta$ lymphocytes, [41] as well as an increase in cytotoxic granule concentrations in TCD8+ lymphocytes.[42] There is evidence of reduced proliferation and differentiation of $T$ and $\mathrm{B}$ lymphocytes in the lymph nodes, [31] with alterations in antibody class change and T lymphocyte overactivation,[42] which can cause cell depletion and lymphocytopenia, leading to a fatal outcome.

The immune system is one the most affected bodily systems in COVID-19,[32] and the generated inflammatory response can be protective or harmful. Excessive or aberrant immune responses are ineffective, result in severe lung injury, and can be life-threatening (Figure 2).[43] The entire immune mechanism is compromised in patients with low-grade inflammation, which has negative effects on the course of the disease.

Low-grade inflammation and immune system dysfunction 'Low-grade inflammation', an expression coined by Krabbe,[44] must be differentiated from the classical concept of acute inflammation, due to differences in their causes and consequences. Low-grade inflammation is generated by stress and tissue dysfunction while acute inflammation is generated by infections and tissue damage. Low-grade inflammation contributes to chronic non-communicable disease pathogenesis, aging and immunosenescence, while acute inflammation helps to eliminate the noxae that initially caused the inflammation and restore homeostasis. [44] Both involve many common mediators; a persistent increase of these common elements is a predictor of mortality. The term 'low-grade' was given to increases in acute-phase reactants, cytokines and leukocytes that do not reach levels typical of acute inflammation. Low-grade inflammation is systemic, subclinical and chronic.[44,45] In COVID-19 patients, it is associated with a high risk of severe disease and high mortality, $[13,14,18]$ which is again increased in older adults (Figure 3).[20,31]

Low-grade inflammation is associated with changes in cell redox status and in cell-death signaling pathways. It increases over time (years) and causes an accumulation of cellular damage.[46] Lowgrade inflammation persists long after the antigenic challenge has passed and continues to damage inflamed tissue, including cells adjacent to inflammatory foci.[44,45] It is perpetuated by positive feedback loops mediated by cytokines, chemokines and sensitized cells.[47] Some of these mediators, such as the pro-inflammatory cytokines IL-1, IL-6, IL-8, IL-13, IL-18, C-reactive protein, tumor necrosis factor alfa (TNF- $\alpha$ ), interferon alfa (IFN- $\alpha$ ) and interferon beta (IFN- $\beta$ ) are at higher levels in older adults and are predictors of chronic non-communicable diseases (Figure 4). $[45,48]$

Patients with low-grade inflammation have impaired barrier systems.[28,50] For example, pulmonary surfactant in lung epithelia is affected, one of whose functions is the regulation of macrophage and monocyte actions.[51] Oxidants generated by myeloperoxidase during inflammatory processes interfere with the function of the SP-D (surfactant protein D) in lung surfactant, damaging host defense, innate immunity and surfactant homeostasis.[52]

COVID-19 infection triggers acute inflammation that overlaps with low-grade inflammation. This results in immune system dysfunction in which control mechanisms are no longer effective, mainly due to $\mathrm{T}$ lymphocyte depletion and changes in signaling pathways. The immune system's dysfunctional response leads to uncontrolled inflammation and multi-system organ damage.[21] COVID-19 predisposes individuals to a chronic inflammatory state 
Figure 3: Immune response dysregulation resulting from chronic low-grade inflammation and SARS-CoV-2 infection ACE2 expression in:

\begin{tabular}{|c|c|c|c|}
\hline $\begin{array}{l}\text { Respiratory } \\
\text { system }\end{array}$ & $\begin{array}{l}\text { Endocrine } \\
\text { system }\end{array}$ & $\begin{array}{l}\text { Immune } \\
\text { system }\end{array}$ & $\begin{array}{l}\text { Cardiovascular } \\
\text { system }\end{array}$ \\
\hline $\begin{array}{l}\text { - Epithelial cells: lung, } \\
\text { nasopharynx, oral and } \\
\text { nasal mucosa } \\
\text { - Type II alveolar cells } \\
\text { - Tissue macrophages } \\
\text { - Dendritic cells }\end{array}$ & $\begin{array}{l}\text { - Adipocytes } \\
\text { - Pancreatic beta cells }\end{array}$ & $\begin{array}{l}\text { - Monocytes } \\
\text { - Macrophages } \\
\text { - Dendritic cells } \\
\text { - T Iymphocytes } \\
\text { - Lymph nodes }\end{array}$ & $\begin{array}{l}\text { - Heart and kidney } \\
\text { epithelial cells } \\
\text { - Cardiomyocytes } \\
\text { - Blood vessel } \\
\text { epithelial cells } \\
\text { - Pericytes }\end{array}$ \\
\hline
\end{tabular}

L

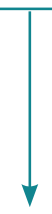

Viral cell load increases when target cells are infected, by:
IMMUNE SYSTEM DYSREGULATION

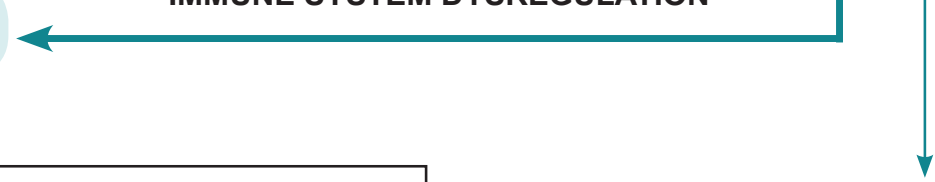

Enhances expression and functioning of viral infection mechanisms

Viral infection exacerbates existing alterations

Chronic inflammation increases viral entry and the rate of viral replication. In turn, the viral infection accentuates pre-existing inflammation and causes excessive responses with systemic repercussions and immune response dysregulation.

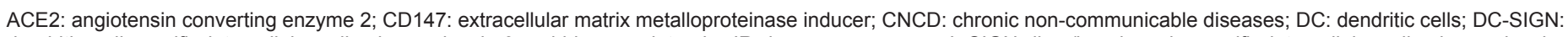

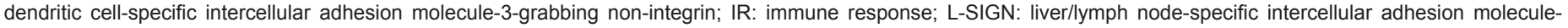
3-grabbing non-integrin type $\mathrm{C}$ lectin receptors; TMPRSS2: serine transmembrane protease 2

mediated by innate immune memory.[36] This process occurs mainly in older adults and patients with pre-existing comorbidities.

Immunosenescence In one study, the median age of COVID-19 patients admitted to intensive care units was 66 years and $80 \%$ of deaths occurred in patients aged $\geq 65$ years, with a case fatality rate of $10 \%-27 \%$ in patients aged $\geq 85$ years. In this study, $69.5 \%$ of older adult patients had underlying pre-existing conditions.[53] Another study, conducted in Ireland and Malaysia, of 663 COVID-19 patients found the mean age of seriously ill and critically ill patients to be 61.3 and 67.0 years, respectively, and the mean age of deceased patients was 69.3 years.[54] Another study of 5700 patients hospitalized with COVID-19 reported a mortality rate of $97.2 \%$ for patients aged $\geq 65$ years who received mechanical ventilation.[55] These data underscore the importance of understanding the effects of aging processes on the immune system.

Cellular senescence is a regulated process that exhibits marked heterogeneity in the dividing potential of individual cells within the population, and even within subpopulations derived from clones. It is triggered by telomere shortening[56] and factors such as oxidative stress, DNA damage, mitochondrial dysfunction, epigenomic stress, radiation and the expression of certain oncogenes.[56,57] Replicative senescence is the cell's inability to continue dividing after a certain number of divisions due to telomeric shortening. [56-59]

During aging, the immune system undergoes quantitative and qualitative decreases in homeostasis, $[59,60]$ which, to some extent, is considered normal physiology.[59,61] These decreases are due to imbalances in cellular proliferation, survival and apoptosis, in addition to depletion of cellular functions.[62] This phenomenon of immune system readjustment and remodeling is known as 'immunosenescence'[61] and is characterized by thymic involution and atrophy or hypoplasia of lymphoid tissues associated with mucosa and skin.[59] Adaptive immunity is impaired, with a reduction in naïve lymphocytes and T lymphocyte diversity, replaced by antigen-experienced quiescent cells.[63]

In immunosenescence, cells involved in innate immunity remain in a baseline state of activation with increased proinflammatory mediators, decreased receptor signaling and decreased effector function.[64] The most notable cellular inflammatory changes occur in macrophages[28,46] with alterations in M1 (conventional) and M2 (repair-suppressor) polarization,[28] cytotoxicity, intracellular death, antigen presentation[64] and nuclear factor kappa light chain enhancer of activated B cells (NF-KB) signal- 
Figure 4: Main inflammatory process generative mechanisms and evolution towards low-grade chronic inflammation

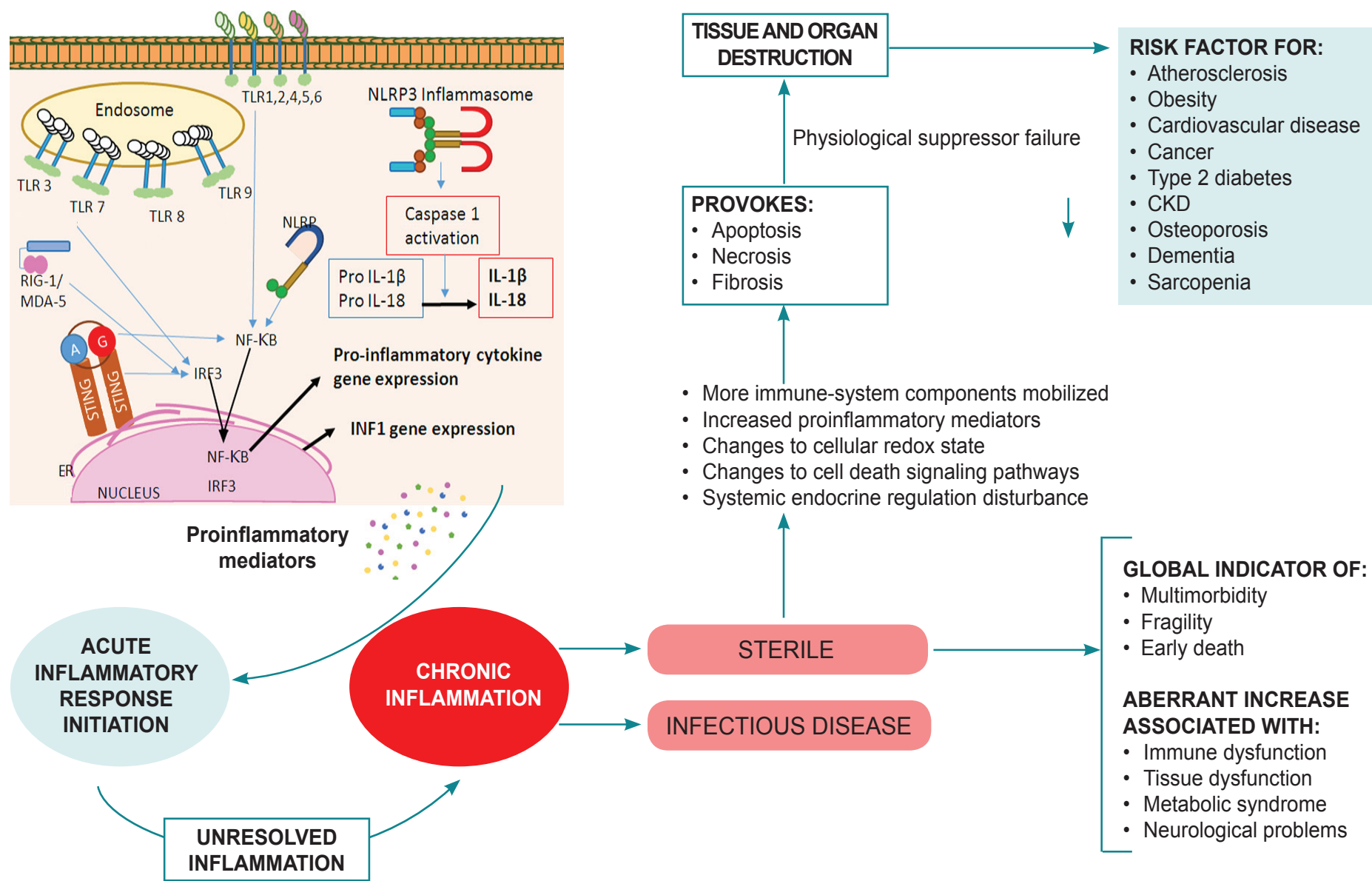

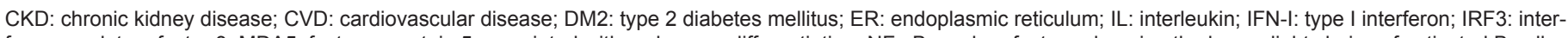

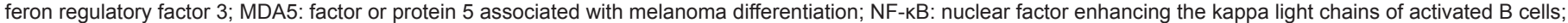

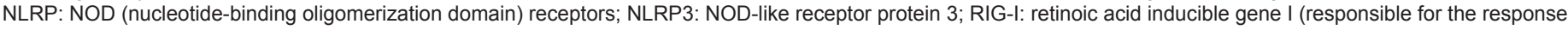
to type 1 interferon); SI: immune system; TING: interferon gene stimulator; TLR: Toll-like receptors

ing, with decreased number and function of Toll-like receptors and antigen-presenting molecules.[46,64] This dysregulation increases the production of pro-inflammatory cytokines such as IL-1 and IL-6, and increases activation levels of NOD-like receptor pyrin domain containing 3 (NLRP3) inflammasomes in alveolar macrophages.[46]

In monocytes, basal cytokine levels are elevated, antigenpresenting molecules are decreased, and phagocytosis changes. [35] In dendritic cells, receptor expression, antigen capture, migratory capacity, functions related to motility, the capacity to activate $T$ cells, and the secretion of cytokines with a decrease in IL-12 and an increase in IL-23 are all affected, while myeloid dendritic cells remain in a semi-activated state that can lead to cytokine secretion even at baseline.[65]

Neutrophils are at the high end of normal limits. Their chemotaxis, respiratory burst resulting in free radical production,[64] microbial functions, phagocytic activity and degranulation capacities are all affected.[66] Neutrophil migration patterns are affected and neutrophil proteinase release occurs, contributing to tissue damage and systemic inflammation.[66] Natural killer (NK) and mature NK cells increase in number,[62] but cytokine secretion decreases[64] (mainly IFN-y)[67] as does perforin production.[66] Although lytic activity is reduced,[62] its overall activity appears to remain intact and stable.[67]

Changes in the balance of $\mathrm{T}$ lymphocyte populations are the result of thymic involution. As part of this alteration, the number of naïve $T$ lymphocytes decreases, memory $T$ lymphocytes accumulate[58] and activated effector cells are dysfunctional and less diverse.[58,63] There is a reduced response to stimulation, and damage to proliferative response with decreased TCD4+ lymphocytes.[62] Functional alterations in Th1 and Th2 lymphocytes produce changes in cytokine secretion with decreases in IL-2 and increases in IL-4 and IL-5.[62] There is also a decrease in naïve TCD8+ lymphocytes and an increase in senescent-memory TCD8+ cells,[68] and therefore a reduction in T cell reserves necessary for protecting the host against novel pathogens.[58,61,69]

Primary antibody responses are weak and short-lived,[67] with lower antibody specificity, affinity and isotype switching.[59] Aging bone marrow has a reduced ability to fully ensure hematopoietic regeneration,[67] which results in peripheral virgin-cell depletion. [63] The spleen suffers a loss of germinal centers and reduction in frequency and size of plasmacytic foci.[67] This results in a decrease in specific antibodies, favoring short-term maintenance of total immunoglobulin levels and serum antibody titers at the 
expense of ability to establish fully functional memory B cell levels.[67] All of this leads to increased levels of pro-inflammatory markers and accumulation of activated dysfunctional effector cells with limited repertoires,[48,59] resulting in age-related inflammation.[28] This is a physiologic response to lifelong antigenic stress, altered mitochondrial function, accumulated oxidative stress and compromised antioxidant defense systems. $[28,46]$

Chronic immune activation, generated in part by persistent antigenic stimulation, contributes to an inflammatory state of multifactorial origin, leading to telomeric erosion and replicative senescence. Replicative senescence, in turn, results in the accumulation of senescent and exhausted T lymphocytes.[28,59] Dysfunctional or hypofunctional cells with terminally differentiated phenotypes express inhibitory molecules such as PD-1 and cytotoxic lymphocyte-associated protein 4 (CTLA-4). $[28,58]$ This depleted phenotype can be also be induced by chronic infections in younger individuals, [70] and can be reversed, at least partially, by therapeutically blocking the immune system's so-called 'checkpoints' (PD-1, CTLA-4, lymphocyte-activation gene 3 or LAG-3, T cell immunoglobulin and mucin domain 3 or TIM-3 and TIMIN).[28]

This knowledge has made it possible to recognize the modifiable nature of some factors involved in immunosenescence. Immunosenescence can be viewed as the result of continuous antigenic challenges[70] induced by inflammatory aging and vice versa,[28] thus understood as two sides of the same coin. [60] The pro-inflammatory state typical of aging is characterized by the accumulation of senescent cells and massive secretion of molecules producing the aptly-named senescence-associated secretory phenotype (SASP).[36] SASP cells produce cytokines, growth factors and proteases that influence neighboring cells, converting them to newly senescent cells through the so-called 'bystander effect.'[56] However, exceptionally successful centenarians are equipped with well-preserved and efficient immune mechanisms, likely through optimal combinations of lifestyle and fortuitous genetics. [61,71]

Healthy centenarians have immune functions similar to those in the young, suggesting that long-lived individuals have less immunosenescence.[70] Keeping chronic low-grade inflammation under tight control is a driving force for longevity due to counterregulation by anti-inflammatory molecules.[28] Centenarians' survival is associated with immune systems that no longer react strongly to persistent infections.[58]

Centenarians possess trained immune system memories regulated by epigenetic changes, the key to controlling the inflammation characteristic of aging.[28] Their peripheral blood mononuclear cells respond well to chemotactic stimuli, and there is an increase in highly active NK (CD16+CD57-) cells with well-preserved cytotoxicity.[61,71] T lymphocytes show an inverted immune risk profile (a high CD4/CD8 ratio and a lower number of CD8+CD282 cells).[50] There is very little autoimmune response, a marked decrease in B lymphocytes,[61] and an almost complete lack of organ-specific autoantibodies.[61,71] Centenarians also have a well-conserved number of T lymphocytes capable of proliferating, but with delayed maximal responsiveness.[61] This delay could constitute a possible risk factor for more severe manifestations of COVID-19, to which we should also add the deterioration of the immune barrier systems that play an important role in natural resistance to infection.
Chronic noncommunicable diseases Since the beginning of the COVID-19 pandemic, many studies have examined the association between its unfavorable clinical evolution and chronic diseases like metabolic disorders, cardiovascular disorders, oncoproliferative diseases and chronic respiratory illnesses, among others.

A meta-analysis of 24 articles including 10,948 COVID-19 patients found that the presence of chronic disease is related to greater COVID-19 severity (OR 3.50) and greater likelihood of intensive care unit (ICU) admission (OR 3.36). The main comorbidities influencing this increase in severity are diabetes mellitus, hypertension, COPD and cardiovascular disease (OR 2.61, 2.84, 3.83 and 4.18, respectively).[14] Another meta-analysis of 43 studies with 3600 patients reported similar results regarding median prevalences of hypertension (16.0\%), diabetes $(10.1 \%)$ and COPD $(2.0 \%)$, but did not relate it to the probability of developing severe forms of COVID-19.[15] Yet another meta-analysis of 19 studies involving 656 COVID-19 patients concluded that the disease is accompanied by high morbidity in chronic disease patients $(36.8 \%$ of patients), among which the most common were hypertension $(18.6 \%)$, cardiovascular disease $(14.4 \%)$ and diabetes $(11.9 \%)$. [16] These data coincide with a study that found that of the total number of COVID-19 cases admitted to ICU, $72.2 \%$ had comorbidities, contrasted with only $27.5 \%$ of patients who did not require ICU admission.[17]

Jain's meta-analysis, reviewing 7 studies involving a total of 1813 COVID-19 patients, found that despite its rarity, COPD carries a high risk for progression to severity (OR 6.42, 95\% Cl 2.44-16.9) and the need for ICU admission (OR 17.8, 95\% $\mathrm{Cl} 6.56-48.2$ ) and is the comorbidity with the highest predictive capacity for these events.[18] A meta-analysis including 1558 COVID-19 patients in 6 studies[72] also found an association between COPD and poor patient progression (OR 5.97). This association is largely due to changes in innate pulmonary defenses, namely those of immune barriers, that characterize COPD.

Total number of COVID-19 deaths is associated with obesity.[73] In a study by Muscogiuri,[74] obesity and morbid obesity were present in $47.6 \%$ and $28.2 \%$, respectively, of patients requiring mechanical ventilation. A meta-analysis by Kumar,[75] including 33 articles and 16,003 patients, showed that diabetics who contract COVID-19 are 2.7 times more likely to develop severe infection and dying than non-diabetics, and that this risk increases with age. Obese or diabetic patients are particularly vulnerable, and the incidence of diabetes mellitus is twice as high in COVID-19 ICU patients than in those who do not require intensive care.[75]

Hu's meta-analysis of 21 studies and 47,344 COVID-19 patients[76] reported a cancer incidence of $1.2 \%$. A similar proportion was reported by El Gohary's meta-analysis of 22 studies, which found $2.1 \%$ of cancer patients among the 11,243 COVID-19 patients involved, of whom $45.4 \%$ had serious or critical manifestations of the disease and $21.1 \%$ died.[77] In Wang's meta-analysis of 138 hospitalized COVID-19 patients, $7.2 \%$ had cancer, $40 \%$ of whom required ICU admission, representing $11.1 \%$ of all 138 cases admitted to the ICU.[17] Liang's study of 1590 COVID-19 patients found that cancer patients infected with SARS-CoV-2 have a 3.5 times higher risk of serious events, including ICU admission or invasive ventilation, than patients without cancer, among whom age $\geq 60$ years is an aggravating factor.[78] Another analysis (of 
6 studies and a total of 1558 patients) failed to find any statistical significance between cancer and severe COVID-19 manifestations ( $p=0.49$ ), despite an OR of 2.3.[72] This variability may be due to differences in neoplasm location, stage, evolution and treatment, which was not taken into account in these analyses.

Metabolic disorders Inflammation stimulated by metabolism, called metainflammation, is an important aspect of metabolic disorders[79] such as obesity, insulin resistance, type 2 diabetes and fatty liver disease.[46] Metabolic imbalances in these diseases coincide with the cellular processes involved in premature aging, suggesting the two may be related.[79]

Obesity Now a global epidemic, obesity involves genetic, epigenetic, hormonal and lifestyle factors,[80] and contributes to development of other metabolic diseases.[74] It is a serious health problem associated with cardiovascular diseases and certain types of cancer,[81] and is accompanied by chronic subclinical inflammatory processes that can affect immune response to infection through direct, indirect and epigenetic mechanisms.[82]

The role adipose tissue physiology plays in the immune system has been understudied.[81] Adipose tissue functions as an endocrine organ that secretes adipokines, growth factors and cytokines,[80] which act in an autocrine or paracrine manner,[46] regulate various metabolic processes[80,81] and modulate inflammation.[48,80] It contains mesenchymal stem cells, stem cells derived from adipocytes, endothelial cells and fibroblasts, which, among others, are responsible for producing extracellular matrices and spontaneous cellular regeneration or induced cell turnover under cellular stress.[79]

Obesity alters the composition, structure and function of adipose tissue,[79] and produces dysfunctional tissue[40,80] whose expansion is accompanied by inflammatory changes that contribute to systemic low-grade inflammation,[80] with inflammatory cell infiltration and endoplasmic reticulum stress production, mitochondrial dysfunction, hypoxia, fibrosis, cell senescence and changes in lipid metabolism.[81] Adipose tissue inflammation initiates systemic inflammation in central (visceral) adiposity.[46] This condition reduces immune cell functionality, results in an imbalance of the intestinal microbiome/virome and induces an inflammatory cytokine phenotype. [82] Macrophages are the main cell type that infiltrate expanding adipose tissue in response to chemokines (MCP-1) produced by hypertrophic adipocytes[80] that increase in number and change location, phenotype and inflammatory characteristics under conditions of obesity.[83] Monocytes, on the other hand, connect low-grade chronic inflammation and altered lipid metabolism through the expression of inflammatory mediators and by modulating intracellular lipid accumulation.[84]

Additionally, TCD4+ and TCD8+ lymphocytes increase, Treg lymphocytes decrease, and this induces a phenotypic shift, recruiting Th1 lymphocytes from the periphery to aid in remodeling the extracellular matrix.[80] This process is associated with fibrosis, insulin resistance and metabolic dysfunction.[79] Th1 lymphocytes secrete interferon, which stimulates production of various chemokines that extend $\mathrm{T}$ lymphocyte migration into adipose tissue, including chemokine $\mathrm{C}-\mathrm{C}$ motif ligand 2 (CCL2), chemokine C-C motif ligand 5 (CCL5), chemokine C-X-C motif ligand 9 (CXCL9) and chemokine C-X-C motif ligand 10 (CXCL10).
Body fat mass increase in children is associated with development of an early immunosenescent profile. Obese children have lower shares of naïve TCD4+ and CD8+ lymphocytes, higher shares of effector memory lymphocytes, and more intermediate TCD8+ lymphocytes and late and senescent TCD4+ lymphocytes; all characteristic of an immunosenescent profile. Obese children also show decreased response to vaccines and increased susceptibility to infection, also characteristic of immunosenescence. [79] Senescence itself impairs normal adipose tissue function and probably contributes directly to the inflammatory characteristics of adipose tissue in obese individuals.[81]

The number of $B$ lymphocytes also increases with body mass index (BMI).[48] The increase in pro-inflammatory $B$ cells is the main driver of the inflammatory profile of $T$ lymphocytes seen in obesity and type 2 diabetes. These cells are characterized by increases in basal secretions of IL- 6 and IFN- $\gamma$, accompanied by marked decreases in IL-10 secretions, a combination that results in chronic low-grade inflammation.[80] Cytokines released by $\mathrm{B}$ cells contribute to phenotypic changes in adipocytes in the abdomen, causing them to release adipokines, other pro-inflammatory markers and cellular debris.[49]

Obese COVID-19 patients experience an interaction between the immune system and adipose tissue, which favors immune system attenuation and chronic inflammation.[82] Proposed mechanisms for the increased severity of the disease in obese patients include reduced end-expiratory volumes, positive endexhalation pleural pressure, low-grade chronic inflammation and altered immune responses to infection.[53] Barrier mechanisms can become compromised by hypoventilation syndrome, obstructive sleep apnea and other mechanical abnormalities caused by excess thoracic and abdominal fatty mass, leading to respiratory complications.[74] Other factors present in obese patients that potentiate severe forms of COVID-19 are an increase in clearly pro-inflammatory Th17 lymphocytes,[82] vitamin $D$ deficiency, $[73,85]$ and intestinal dysbiosis, $[74,85]$ which can also impact respiratory system mucosa, affecting their function as protective barriers.[28,48.74] These last two risk factors are modifiable and possible points of preventive intervention, including vitamin $D$ therapeutic supplements and consumption of prebiotics and probiotics that can effectively restore healthy gut microbiota. However, as these interventions require long treatment periods before benefits are accrued, they would have little impact during the course of a SARS-CoV-2 infection.

SARS-CoV-2 can infect subcutaneous and visceral adipose tissue, since angiotensin-converting enzyme 2 (ACE2) expression levels are higher in these tissues than in lung tissue.[86,87] Additionally, in obese patients, angiotensin-converting enzyme 1 (ACE1) increases, ACE2 is inhibited, and angiotensin II activates angiotensin I and II receptors, mediating a pro-inflammatory response and a consequent increase in vascular permeability.[82] Adipose tissue may act as a reservoir for the virus and may contribute to viral shedding, increased immune activation and cytokine amplification, explaining obese COVID-19 patients' poor prognoses.[73]

Type 2 diabetes mellitus There has been a parallel increase in the incidences of obesity and diabetes, to the point that diabetes is often considered a comorbidity of obesity.[80] Individuals with this type of diabetes experience both inflammation and metainflammation, most frequently seen in older adults in whom immune dis- 
orders overlap with immunosenescence. Type 2 diabetes driven by inflammation is observed at an early age, suggesting that it is a model of premature immunosenescence, as senescent or latedifferentiated $\mathrm{T}$ lymphocytes predict development of hyperglycemia in humans. Additionally, a feature common to both diabetes and old age is a decrease in naïve TCD4+ lymphocytes, with an increase in memory TCD4+ lymphocytes and effector TCD4+ and TCD8+ lymphocytes.[79]

The immune system is compromised in diabetic patients, especially innate immunity,[88] with phagocytic cell dysfunction and neutrophil chemotaxis inhibition, leading to an uncontrolled inflammatory response, increased levels of enzymes related to tissue damage and states of hypercoagulation, significantly elevated serum levels of inflammatory biomarkers and a proinflammatory cytokine profile.[74] Transient hyperglycemia may temporarily affect the innate immune system's response to infection,[88] as it serves as a trigger for proinflammatory cytokines in innate immune cells, particularly IL-1, IL-6 and TNFa.[79] One mechanism of immune impairment driven by hyperglycemia is the overactivation of the advanced glycosylation end-product pathway and its receptors. Additionally, elevated levels of glycated hemoglobin are associated with decreased phagocytic activity in circulating monocytes and neutrophils.[79] Therefore, maintaining optimal glycemic control in COVID-19-positive diabetics can help to prevent complications and more severe manifestations of the disease.

Factors contributing to disease severity in COVID-19-positive diabetics include hyperglycemia, impaired immune function, suboptimal glycemic control during hospitalization, prothrombic and proinflammatory states, $[53,88]$ and reduced forced vital capacity (FVC) and forced expiratory volume in one second (FEV1) in pulmonary function tests.[88] Fatty liver disease frequency in type 2 diabetics may increase the risk of an exaggerated immune response, including development of a cytokine storm, which is associated with severe lung injury in COVID-19 patients.[53]

Current evidence does not support the conclusion that diabetics are more susceptible to developing SARS-CoV-2 infection, but they are more likely to have more severe clinical manifestations. [88] In turn, COVID-19 can induce diabetes by either increasing insulin resistance or by direct damage to the islets of Langerhans,[38] which have abundant viral ACE2 receptors (detectable by immunostaining),[69] whose damage leads to reduced insulin release.[88] ACE2 and dipeptidyl peptidase-4 (DPP4), in addition to acting as receptor proteins for the SARS-CoV-2 virus, are also metabolic signal transducers that participate in pathways that regulate inflammation, renal and cardiovascular physiology and glucose homeostasis.[88] SARS-CoV-2 infection can cause sharp fluctuations in blood glucose levels, and glucose metabolism dysregulation both exacerbates diabetes and increases infection severity.[88] The resulting proinflammatory environment and possible cytokine storm exacerbate existing inflammation and result in systemic inflammation with serious consequences,[74] compounding damage already present in diabetic patients.[38]

Cardiovascular disease Hypertension is one of the most common diseases worldwide, and is considered a silent killer.[89] It is the most common modifiable risk factor in cardiovascular disease,[90] frequently coexisting with other comorbidities and with no apparent cause in $90 \%$ of cases.[91]
The immune system plays an important role in hypertension[92] via low-grade inflammation in the kidneys, the arterial wall, the central nervous system,[93] the sympathetic nervous system[91] and the heart,[92] which favor both development and increased severity of hypertension.[93] Low-grade inflammation has been considered both a cause and a consequence of hypertension. [90] In chronic inflammation, innate and adaptive immune cells are activated, cause organ and tissue damage through production of various cytokines and chemokines,[91] contributing to further immune system dysfunction, blood pressure elevation and vascular remodeling.[92]

Other changes in hypertensive individuals include increased pattern recognition receptors; NK cell migration toward the aortic wall; increased serum levels of complement proteins C3a and C5a;[90] increased cyclic dilation of larger vessels; release of IL-6, IL-8, endothelin and other proinflammatory mediators; and increased endothelial expression of VCAM-1, ICAM-1 and cluster of differentiation 40 (CD40).[91] These changes enhance activation of adjacent monocytes, macrophages and dendritic cells. T cell receptors, adregenic receptors and mineralocorticoid receptors on CD8+ cells play important roles in promoting IFN-y production.[91] The TCD4+ immune response is polarized toward Th1 and Th17 phenotypes, IL-17 secretors and other cytokines involved in hypertensive inflammatory mechanisms.[90]

T lymphocyte polarization-which also occurs in antiviral response-can elicit exaggerated immune responses in hypertensive patients. Poor blood pressure control leads to increased dysregulation of the immune system.[42] Hypertension results in increased blood levels of monocytes, eosinophils and neutrophils.[92] A relationship has been suggested between increased lymphocyte levels and hypertension.[92] CD8+ T lymphocyte dysfunction caused by increased immunosenescent, proinflammatory and cytotoxic CD8+ T lymphocytes has been observed in hypertensive patients.[83,94] These lymphocytes cannot effectively fight viral infections,[42] and increase production of IFN- $\gamma$, TNF- $\alpha$ and the cytotoxic molecules granzyme B and perforin, [91,94] contributing to the pathological overproduction of cytokines that occurs in low-grade inflammation.[42]

Animal models suggest that lymphocytic effects may also be modulated by vascular function, blood flow and sympathetic nervous system activation. Endothelial dysfunction favors the recruitment and activation of monocytes and antigen-presenting cells that facilitate inflammation through the release of pro-inflammatory cytokines, which increases endothelial dysfunction, closing a vicious circle in hypertension pathogenesis.[92] Effective antihypertensive treatment is believed to help restore dysregulated immune systems in hypertensive patients.[42] Accordingly, normalizing blood pressure in hypertensive patients can help avoid COVID-19 complications in these patients.

Possible mechanisms of myocardial injury in COVID-19 patients include entrance of the SARS-CoV-2 virus through myocardial ACE2 receptors, hypoxia, and cytokine storm-induced monocyte damage.[88] Cardiac consequences of SARS-CoV-2 infection range from cardiac arrhythmias and hypotension to acute coronary events and heart failure with cardiogenic shock.[42,88] Myocardial injury may be due to viral colonization, cytokine storms,[39] atherosclerotic plaque rupture, hypoxic injury, coronary spasms, 
formation of microthrombi, or direct vascular or endothelial injury. [88] Biopsies have shown low-grade myocardial inflammation[39] with interstitial edema[88] and viral particles in and around interstitial cytopathic macrophages but not in cardiomyocytes.[39] COVID-19 can trigger subclinical autoimmune myocarditis, and myocardial damage can cause a de novo autoimmune reaction (Figure 2).[42]

SARS-CoV-2 can destabilize or even shed atherosclerotic plaques during profound systemic inflammatory responses, cytokine storms, hemodynamic changes, or the polarization of immune cells toward more unstable phenotypes.[39,42] These processes, in conjunction with cytokine circulation in the heart and reduced oxygen supply, can cause coronary microvasculature dysfunction with inflammatory cardiomyopathy or atherothrombosis, leading to the acute coronary syndrome seen in deceased patients.[39]

Oncoproliferative diseases Oncogenesis is an extremely complex process that involves immune, genetic and exogenous factors.[62] Rudolf Virchow first described the association between cancer and inflammation in 1863.[95] Inflammatory immune responses can be tumorigenic or antitumorigenic, depending on delicate balances between innate and adaptive immune system responses influenced by environmental and microenvironmental conditions.[96-98] A healthy, regulated immune response is considered antitumoral, while uncontrolled and excessive responses can induce chronic inflammation and proto-oncogenic conditions. [97] Low-grade inflammation associated with persistent infection may be carcinogenic.[96,99,100] Genetic and epigenetic factors also play a role in carcinogenesis.[101]

Chronic inflammation can trigger altered oncogene and tumorsuppressor gene expression.[96] This inflammation is associated with environmental factors, which, together with somatic mutations, are responsible for $90 \%$ of all cancers.[98] Chronic inflammation leads to structure loss and excessive tissue remodeling and DNA modification due to oxidative stress, increasing cancer risk.[101] Chronic inflammation is also implicated in obesity-related cancers like those of the liver and pancreas, $[98,96]$ and obese patients are 1.6 times more likely to develop these cancers.[98] This inflammation is accompanied by elevated levels of insulin, glucose, leptin, C-reactive protein and IL-6, which can contribute to worse prognoses for overweight or obese COVID-19 patients.[99] Inflammation may also be involved in higher incidences of cancer in older adults. The aging microenvironment, notable within the tumor microenvironment, plays a key role in reprogramming tumor cells toward secretory phenotypes associated with senescence that have tumorigenic effects such as increased malignant phenotypes and tumor induction.[79]

Tumor-associated inflammation develops in tumorigenic microenvironments,[100] in which tumor-promoting immunity and antitumor immunity coexist.[101] In these microenvironments, there are elevated levels of inflammatory mediators, RNOS, microRNAs, and increased cyclooxygenase- 2 activity that facilitate inflammation-mediated tumorigenesis.[96,99] The normal processes of cell proliferation, senescence and apoptosis are also affected, as are DNA mutation and methylation rates.[99] Proinflammatory mediators induce several molecular-signaling cascades that promote inflammatory states.[96] IL-23, secreted by Th17 lymphocytes, is a key factor in maintaining and expanding tumorigenic Th17 inflammatory cells, promoting inflammation, angiogenesis and reducing TCD8+ lymphocytes within the tumor microenvironment. [96] All these processes and factors have systemic repercussions, reduce the immune response to SARS-CoV-2 and favor uncontrolled inflammation that can lead to cytokine storms in already immunosuppressed patients.

Cancer patients are more susceptible to SARS-CoV-2 infection due to systemic immunosuppression caused by malignancy and treatment.[78] Cancer patients who have undergone major surgery, chemotherapy, radiation therapy and immunotherapy are at increased risk of contracting COVID-19, and its sequelae,[102] as are patients with lung, hematologic or metastatic cancers.[43,103] Anemia and hypoproteinemia have been found in COVID-19-positive cancer patients, a result of nutritional deterioration that negatively affects immunity and increases susceptibility to respiratory pathogens.[103] Lung cancer patients, who have impaired lung function and resistance, have high probabilities of developing severe anoxia and rapidly progressing to critical condition or death from COVID-19.[43,103] Chronic lung inflammation favors increased proinflammatory cytokines,[43] and poor immune response allows for viral spread, tissue destruction and progression to severe stages of the disease.[33]

Respiratory diseases COPD and asthma are the two most common and dangerous airway diseases.[104] Both are characterized by the presence of chronic inflammation.[105,106] These patients present with changes to lung anatomy and to the blood vessels that feed them.[88]

COPD Chronic obstructive pulmonary disease causes limitations in airflow and is associated with chronic airway and lung inflammation.[51] Other comorbidities are found in $60 \%-90 \%$ of COVID-19-positive COPD patients, aggravating symptoms and worsening disease prognosis.[37]

Defense barrier changes are observed in COPD pathology,[51] mainly failures in mucociliary mechanisms due to hair cell destruction, the presence of dehydrated mucus with changes to normal biophysical properties and mucin hypersecretion. [40] Low-grade inflammation is behind many of the changes caused by COPD, such as destruction of lung parenchyma and parenchymal vasculature, normal tissue repair disruption, small airway fibrosis and alveolar rupture.[51] This inflammation is characterized by an inadequate immune response with increases in neutrophils, macrophages, Th1 lymphocytes, B lymphocytes, vascular endothelial cadherins, platelet endothelial-cell adhesion molecules and E-selectin. These increases are associated with lung destruction and airflow limitation.[51] The protease/antiprotease relationship is altered, causing neurogenic damage and abnormalities in apoptotic, catabolic and senescent mechanisms. Imbalances between oxidizing and antioxidant agents causes activation of kinases and transcription factors, inflammatory mediator release, cell damage and apoptosis. Involved oxidants include reactive oxygen species (ROS) that damage cells, inactivate defense mechanisms, initiate inflammation and increase oxidative stress.[51]

COPD patients have increased ACE2 receptors in small airways,[107] but some authors argue that this may be mediated 
in the case of COVID-19 by the use of corticosteroid inhalants, which could limit lung damage in SARS-CoV-2 infection.[108] However, in COVID-19 animal models, ACE2 loss or deficiency is associated with lung injury,[35,109] and causes inflammation,[35] increased vascular permeability and acute respiratory distress syndrome.[109] Pre-existing endothelial damage to pulmonary capillaries is accentuated and leads to lung destruction, cardiovascular disease and cerebrovascular damage.[51] Pulmonary endothelial damage is considered the hallmark of acute respiratory distress syndrome.[38]

Asthma Bronchial asthma is a heterogenous disease characterized by chronic airway inflammation and variable remodeling, with a variety of clinical presentations and responses to treatment. [110] Most viral infections exacerbate asthma,[104,111,112] generally by inducing Th2-mediated responses, and high levels of proinflammatory cytokines and proinflammatory cytokine receptors.[111] Many of these reactions also appear during acute asthma attacks.

Several studies report that SARS-CoV-2 infection does not exacerbate asthma attacks, $[111,113,114]$ and it is not associated with increased risks of hospitalization, severity or mortality, compared to patients without asthma.[114-116] Asthmatic patients generally have more comorbidities; however, greater severity and higher mortality levels have not been seen in COVID-19-positive asthmatics.[88,104,117] This may not be contradictory, as the course of COVID-19 in asthmatics depends on the persistence and severity of the patient's asthma. To avoid or reduce risk of COVID-19 complications in asthmatics, it is important to control both the asthma and its inter-crisis treatment, which prevents structural and functional damage to the tracheobronchial tree.

Different asthma phenotypes show varying susceptibility to and severity of COVID-19.[116] In patients with type 2 asthma, we see chronic eosinophilic type 2 inflammation, the most common form of inflammation in asthma.[104,118] Type 2 asthmatics suffer from bronchial obstruction due to infiltration of innate immunity cells (primarily eosinophils, neutrophils, mast cells and macrophages)[104] and secretion of cytokines by innate immunity cells that shifts the immune response toward production of Th2 lymphocytes, type 2 B lymphocytes and allergen-specific IgE, which, in turn, perpetuates the inflammatory response.[106] Other mechanisms involved in persistent asthma are disruptions in inflammation resolution due to prolonged mast cell and eosinophil survival, decreases in lipoxin A4 in asthmatic airways, responsible for eosinophil apoptosis and for decreasing type 2 innate lymphoid cells (ILC2), and in NK cell activity.[119]

It has been hypothesized that the type 2 inflammatory response in asthmatics behaves differently than those of other pathologies,[10] and that it may act as a protective factor against COVID-19 contraction and progression,[120] due to Th2-biased immunity with cross-regulation between allergic immunity and altered interferonmediated responses,[118] due to decreased production of bronchial epithelial cells and plasmacytoid dendritic cells.[106] The Th2-dominant environment is capable of regulating the late-phase hyperinflammation that typically marks severe respiratory viral diseases, but immunopathological processes are the hallmark of tissue damage.[118]
There are various schools of thought regarding ACE2 receptor involvement in SARS-CoV-2 infection in asthmatics. Calvielli suggests ACE2 expression is different in different types of asthma.[121] Other researchers suggest that respiratory epithelial cells in asthmatics show decreased ACE2 receptor gene expression, $[120,122]$ and that this decrease overrides the minimal increase in transmembrane protease serine 2 (TMPRSS2) gene expression.[122] The reduced expression of the SARSCoV-2 receptor could be due to the fact that IL-13 is involved in recruiting eosinophils in bronchial epithelia,[123] which can reduce ACE2 expression in human bronchial tissue (observed ex vivo).[120] ACE2 receptor expression is lower in patients with high allergic sensitization.[123,124] In contrast, patients with non-type 2 asthma have inflammatory profiles featuring Th1 and Th17 lymphocytes.[116,119] Non-type 2 asthmatics' molecular phenotype is characterized by metabolic and mitochondrial pathways associated with the inflammasome and is generally accompanied by comorbidities like obesity, type 2 diabetes and hypertension. As they have low blood eosinophil numbers,[116] and ACE2 and TMPRSS2 gene expression levels similar to those in healthy people,[123,124] these asthmatics are susceptible to developing more severe forms of COVID-19.[116]

Scope, limitations and clinical implications of the review COVID-19 research generates such a volume of information that any review article runs the risk of missing important results. Many reviews only include articles written and published in English; this work also includes articles written in Spanish, but not in languages other than Spanish and English. This review focused on intersections of the immune system, low-grade inflammation and COVID-19 immunopathology with chronic diseases and age; other diseases that directly affect the immune system-such as immunodeficiencies or autoimmune diseases-were not included, nor were other chronic diseases such as kidney or neurogenerative diseases.

This review summarizes the main immunopathological alterations of the most frequent comorbidities described in COVID-19 patients, which directly influence the clinical course of the disease. This can aid patient management in clinical practice by identifying possible preventive actions designed to mitigate potential complications or progression to more severe manifestations of the disease.

\section{FINAL CONSIDERATIONS}

Low-grade chronic inflammation is characterized by a proinflammatory state with endothelial dysfunction and changes to the immune system, mainly in the innate immune response, with increases of proinflammatory mediators that generate pathogenic conditions and prevent elimination of the virus by triggering a dysregulated immune response. Inflammation is a common factor in non-communicable chronic diseases like obesity, type 2 diabetes, hypertension, cancer and COPD, all of which are risk factors for developing severe forms of COVID-19. Such risk is markedly increased when several of these factors occur in persons aged $\geq 60$ years, except for those with type 2 bronchial asthma, where chronic eosinophilic inflammation protects against SARS-CoV-2 infection due to decreased interferonmediated response and a reduction in ACE2 receptors. The links between immunosenescence, chronic disease and altered immune response in COVID-19 deserves continued attention by researchers. $-1 /$ - 


\section{REFERENCES}

1. Sun J, He W-T, Wang L, Lai A, Ji X, Zhai X, et al. COVID-19: epidemiology, evolution, and crossdisciplinary perspectives. Trends Mol Med. 2020 May 1;26(5):483-95.

2. Huang C, Wang Y, Li X, Ren L, Zhao J, Hu Y, et al. Clinical features of patients infected with 2019 novel coronavirus in Wuhan, China. Lancet. 2020 Feb 15;395(10223):497-506.

3. Han $Q$, Lin Q, Jin S, You L. Coronavirus 2019nCoV: a brief perspective from the front line. J Infect. 2020 Apr 1;80(4):373-7.

4. Fuk-Woo CJ, Kok K, Zhu Z, Chu H, Kai-Wang TK, Yuan S, et al. Genomic characterization of the 2019 novel human pathogenic coronavirus isolated from a patient with atypical pneumonia after visiting Wuhan. Emerg Microbes Infect. 2020 Jan 28:9(1):221-36.

5. Shereen MA, Khan S, Kazmi A, Bashir N, Siddique R. COVID-19 infection: origin, transmission, and characteristics of human coronaviruses. J Adv Res. 2020 Mar 16;24:91-8.

6. Wu D, Wu T, Liu Q, Yang Z. The SARS-CoV-2 outbreak: what we know. Int J Infect Dis. 2020 May;94:44-8

7. Hoque MN, Chaudhury A, Akanda MdAM, Hossain MA, Islam Md Tofazzal. Genomic diversity and evolution, diagnosis, prevention, and therapeutics of the pandemic COVID-19 disease. Peer J. 2020 Sep 1;8:e9689. DOI: 10.7717/peerj.9689

8. Ovsyannikova IG, Haralambieva IH, Crooke SN, Poland GA, Kennedy RB. The role of host genetics in the immune response to SARSCoV-2 and COVID-19 susceptibility and severity. Immunol Rev. 2020 Jul;296(1):205-19.

9. Gill SE, Dos Santos CC, O'Gorman DB, Carter DE, Patterson EK, Slessarev M, et al. Transcriptional profiling of leukocytes in critically ill COVID19 patients: implications for interferon response and coagulation. Intensive Care Med Exp. 2020 Dec 11;8:75. DOI: 10.1186/s40635-020 $-00361-9$

10. McCoy K, Peterson A, Tian Y, Sang Y. Immunogenetic association underlying severe COVID-19. Vaccines (Basel). 2020 Nov 20;8(4):700

11. Di Maria E, Latini A, Borgiani P, Novelli G. Genetic variants of the human host influencing the coronavirus-associated phenotypes (SARS, MERS and COVID-19): rapid systematic review and field synopsis. Hum Genomics. 2020 Sep 11;14(1):30.

12. Kenney AD, Dowdle JA, Bozzacov L, McMichael TM, Gelais CS, Panfil AR, et al. Human genetic determinants of viral diseases. Annu Rev Genet. 2017 Nov 27:51:241-63.

13. Wang X, Fang X, Cai Z, Wu X, Gao X, Min $J$, et al. Comorbid chronic diseases and acute organ injuries are strongly correlated with disease severity and mortality among COVID-19 patients: a systemic review and meta-analysis. Research (Wash DC). 2020;2402961. DOI: 10.34133/2020/2402961

14. Liu H, Chen Sh, Liu M, Nie H, Lu H. Comorbid chronic diseases are strongly correlated with disease severity among COVID-19 patients: a systematic review and meta-analysis. Aging Dis. 2020 May 9;11(3):668-78

15. Fu L, Wang B, Yuan T, Chen X, Ao Y, Fitzpatric $T$, et al. Clinical characteristics of coronavirus disease 2019 (COVID-19) in China: a systematic review and meta-analysis. J Infec. 2020 Jun;80(6):656-65.

16. Rodríguez-Morales AJ, Cardona-Ospina JA, Gutiérrez-Ocampo E, Villamizar-Peña R, Holguín-Rivera Y, Escalera-Antezana JP, et al. Clinical, laboratory and imaging features of COVID-19: a systematic review and metaanalysis. Travel Med Infect Dis. 2020 Mar-
Apr;34:101623. DOI: 10.1016/j.tmaid.2020.10 1623

17. Wang D, Hu B, Hu C, Zhu F, Liu X, Zhang J, et al. Clinical characteristics of 138 hospitalized patients with 2019 Novel Coronavirus-infected pneumonia in Wuhan, China. JAMA. 2020 Mar 17;323(11):1061-9.

18. Jain V, Yuan JM. Predictive symptoms and comorbidities for severe COVID-19 and intensive care unit admission: a systematic review and meta-analysis. Int J Public Health. 2020 Jun;65(5):533-46.

19. Kang SJ, Jung SI. Age-related morbidity and mortality among patients with COVID-19. Infect Chemother. 2020 Jun;52(2):154-64.

20. Shahid Z, Kalayanamitra R, McClafferty B Kepko D, Ramgobin D, Patel R, et al. COVID-19 and older adults: what we know. J Am Geriatr Soc. 2020 May;68(5):926-9.

21. Tay MZ, Poh CM, Rénia L, MacAry PA, Ng LFP. The trinity of COVID-19: immunity, inflammation and intervention. Nat Rev Immunol. 2020 Jun;20(6):363-74.

22. Comunicado de Prensa. Creciendo a un ritmo menor, se espera que la población mundial alcanzará 9.700 millones en 2050 y un máximo de casi 11.000 millones alrededor de 2100: Informe de la ONU [Internet]. New York: United Nations, Department of Public Information; 2019 [cited 2020 Dec 24]. 4 p. Available at: https://population.un.org/wpp/Publications/Files/ WPP2019 PressRelease ES.pdf. Spanish.

23. World Health Organization [Internet]. Geneva: World Health Organization; c2021. Newsroom. Fact sheets. Enfermedades no transmisibles; [updated 2018 Jun 1; cited 2020 Dec 24]. Available at: https://www.who.int/es/news-room/ fact-sheets/detail/noncommunicable-diseases. Spanish.

24. National Health Statistics and Medical Records Division (CU). Anuario Estadístico de Salud 2019 [Internet]. Havana: Ministry of Public Health (CU); 2020 [cited 2020 Dec 24]. 206 p. Available at: http://www.sld.cu/anuncio/2020/05/09/ publicado-el-anuario-estadistico-de-salud-2019. Spanish.

25. Horton R. Offline: COVID-19 is not a pandemic. Lancet. 2020 Sep 26;396(10255):874.

26. Prete M, Favoino E, Catacchio G, Racanelli V, Perosa F. SARS-CoV-2 Inflammatory Syndrome. Clinical features and rationale for immunological treatment. Int J Mol Sci. 2020 May 10;21(9):3377.

27. Abbas AK, Litchman AH, Pillai S. Inmunología celular y molecular. 8va. ed. Barcelona: Elsevier España; 2015. Chapter 1, Propiedades y generalidades de las respuestas inmunitarias; p. 1-12. Spanish.

28. Fulop T, Larbi A, Dupuis G, Le Page A, Frost $\mathrm{EH}$, Cohen AA, et al. Immunosenescence and inflamm-aging as two sides of the same coin: friends or foes? Front Immunol. 2018 Jan 10;8:1960. DOI: 10.3389/fimmu.2017.01960

29. Vabret N, Britton GJ, Gruber C, Hegde S, Kim J, Kuksin M, et al. Immunology of COVID-19: current state of the science. Immunity. 2020 Jun 16;52(6):910-41.

30. Jonsdottir HR, Dijkman R. Coronaviruses and the human airway: a universal system for virus-host interaction studies. Virol J. 2016 Feb 6:13:24 DOI: 10.1186/s12985-016-0479-5

31. Nikolich-Zugich J, Knox KS, Tafich Rios C, Natt $B$, Bhattacharya D, Fain MJ. SARS-CoV-2 and COVID-19 in older adults: what we may expect regarding pathogenesis, immune responses, and outcomes. GeroScience. 2020 Apr;42(2):505-14.

32. Jafarzadeh A, Chauhan P, Saha B, Jafarzadeh S, Nemati M. Contribution of monocytes and macrophages to the local tissue inflammation and cyto- kine storm in COVID-19: Lessons from SARS and MERS, and potential therapeutic interventions. Life Sci. 2020 Sep 15;257:118102. DOI: 10.1016/j.Ifs.2020.118102

33. Rohit G, Abdou Y, Singh A, Rana N, Puzanov Ernstoff MS. COVID-19 and cancer: a comprehensive review. Curr Oncol Rep. 2020 May 8:22(5):53. DOI: 10.1007/s11912-020-00934-7

34. Zhang D, Guo R, Lei L, Liu H, Wang Y, Wang Y, et al. COVID-19 infection induces readily detectable morphologic and inflammation-related phenotypic changes in peripheral blood monocytes. J Leukoc Biol. 2021 Jan;109(1):13-22.

35. Pence BD. Severe COVID-19 and aging: are monocytes the key? GeroScience. 2020 Aug;42(4):1051-61.

36. Bektas A, Schurman SH, Franceschi C, Ferrucci L. A public health perspective of aging: do hyperinflammatory syndromes such as COVID-19, SARS, ARDS, cytokine storm syndrome, and post-ICU syndrome accelerate short- and longterm inflammaging? Immun Ageing. 2020 Aug 24;17:23 DOI: 10.1186/s12979-020-00196-8

37. Figueira Gonçalves JM, Golpe R. Clinical challenges in chronic obstructive pulmonary disease in patients who suffered SARS-CoV-2 infection. Med Clin (Barc). 2020 Aug 28;155(4):162-4. English, Spanish.

38. Sardu C, Gambardella J, Morelli MB, Wang X, Marfella R, Santulli G. Hypertension, thrombosis, kidney failure, and diabetes: is COVID-19 an endothelial disease? A comprehensive evaluation of clinical and basic evidence. J Clin Med. 2020 May;9(5):1417. DOI: 10.3390/jcm9051417

39. Matsushita K, Marchandot B, Jesel L, Ohlmann P, Morel O. Impact of COVID-19 on the cardiovascular system: a review. J Clin Med. 2020 May;9(5):1407. DOI:10.3390/jcm9051407

40. Mattioli AV, Puviani MB, Nasi M, Farinetti A. COVID-19 pandemic: the effects of quarantine on cardiovascular risk. Eur J Clin Nutr. 2020 Jun;74(6):852-5.

41. Mathew D, Giles JR, Baxter AE, Oldridge DA Greenplate AR, Wu JE, et al. Deep immune profiling of COVID-19 patients reveals distinct immunotypes with therapeutic implications. Science. 2020 Sep 4;369(6508):eabc8511. DOI: 10.1126/ science.abc8511

42. Guzik TJ, Mohiddin SA, Dimarco A, Patel V, Savvatis K, Marelli-Berg FM, et al. COVID-19 and the cardiovascular system: implications for risk assessment, diagnosis, and treatment options. Cardiovasc Res. 2020 Aug 1;116(10):1666-87.

43. Addeo A, Friedlaender A. Cancer and COVID-19: unmasking their ties. Cancer Treat Rev. 2020 Aug;88:102041. DOI: 10.1016/j.ctrv.2020.102041

44. Krabbe KS, Pedersen M, Bruunsgaard H. Inflammatory mediators in the elderly. Exp Gerontol. 2004 May;39(5):687-99.

45. Medzhitov R. Origin and physiological roles of inflammation. Nature. $2008 \mathrm{Jul}$ 24;454(7203):428-35

46. Chung HY, Kim DH, Lee EK, Chung KW, Chung $\mathrm{S}$, Lee $\mathrm{B}$, et al. Redefining chronic inflammation in aging and age-related diseases: proposal of the senoinflammation concept. Aging Dis. 2019 Apr 1;10(2):367-82

47. Hawiger J, Zienkiewicz J. Decoding inflammation, its causes, genomic responses, and emerging countermeasures. Scand J Immunol. 2019 Dec;90(6):e12812. DOI: 10.1111/sji.12812

48. Ferrucci L, Fabbri E. Inflammageing: chronic inflammation in ageing, cardiovascular disease, and frailty. Nat Rev Cardiol. 2018 Sep;15(9):505-22.

49. Rock KL, Latz E, Ontiveros F, Kono H. The sterile inflammatory response. Annu Rev Immunol. 2010;28:321-42. DOI: 10.1146/annurev-immu nol-030409-101311. 
50. Bektas A, Schurman SH, Sen R, Ferrucci L. Human $T$ cell immunosenescence and inflammation in aging. J Leukoc Biol. 2017 Oct;102(4):977-88.

51. Martínez-Aguilar NE, Vargas-Camaño ME, Hernández-Pliego RR, Chaia-Semerena GM Pérez-Chavira MR. Inmunopatología de la enfermedad pulmonar obstructiva crónica. Rev Alerg Mex. 2017;64(3):327-46. Spanish.

52. Crouch EC, Hirche TO, Shao B, Boxio R, Wartelle J, Benabid R, et al. Myeloperoxidasedependent inactivation of surfactant protein $\mathrm{D}$ in vitro and in vivo. J Biol Chem. 2010 May 28;285(22):16757-70.

53. Flaherty GT, Hession $\mathrm{P}$, Liew $\mathrm{CH}$, Wei Lim BC, Leong TK, Lim V, et al. COVID-19 in adult patients with preexisting chronic cardiac, respiratory and metabolic disease: a critical literature review with clinical recommendations. Trop Dis Travel Med Vaccines. 2020 Aug 28;6:16 DOI:10.1186/s40794-020-00118-y

54. Zhang J, Wang X, Jia X, Li J, Hu K, Chen G, et al. Risk factors for disease severity, unimprovement, and mortality in COVID-19 patients in Wuhan, China. Clin Microbiol Infect. 2020 Jun;26(6):767-72

55. Richardson S, Hirsch JS, Narasimhan M Crawford JM, McGinn T, Davidson KW, et al Presenting characteristics, comorbidities, and outcomes among 5700 patients hospitalized with COVID-19 in the New York City area. JAMA. 2020 May 26;323(20):2052-9.

56. Kowald A, Passos JF, Kirkwood TBL. On the evolution of cellular senescence. Aging Cell. 2020 Dec;19(12):e13270. DOI: 10.1111 / acel.13270

57. Hamsanathan S, Alder JK, Sellares J, Rojas M, Gurkar AU, Mora AL. Cellular senescence: the Trojan horse in chronic lung diseases. Am J Respir Cell Mol Biol. 2019 Jul;61(1):21-30.

58. Nikolich-Zugich J. Ageing and life-long maintenance of T-cell subsets in the face of latent persistent infections. Nat Rev Immunol. 2008 Jul;8(7):512-22.

59. Suárez GM, Saavedra D. Manipulación de la inmunosenescencia. Rev Cubana Hemato Inmunol Hemoter [Internet]. 2018 Jan-Mar [cited 2020 Dec 24];34(1):33-41. Available at: http:// www.revhematologia.sld.cu/index.php/hih/arti cle/view/584/767. Spanish.

60. Thomas R, Wang W, Su DM. Contributions of age-related thymic involution to immunosenescence and inflammaging. Immun Ageing. 2020 Jan 20;17:2. DOI: 10.1186/s12979-020-0173-8

61. Franceschi C, Monti D, Barbieri D, Salvioli S, Grassilli E, Capri M, et al. Successful immunosenescence and the remodeling of immune responses with ageing. Nephrol Dial Transplant. 1996;11 Suppl 9:18-25.

62. Motta M, Ferlito L, Malaguarnera L, Vinci E, Bosco S, Maugeri D, et al. Alterations of the lymphocytic set-up in elderly patients with cancer. Arch Gerontol Geriatr. 2003 Jan-Feb;36(1):7-14

63. GarcíaB, LageA. Inmunosenescencia: implicaciones para la inmunoterapia de cáncer en los adultos mayores. Biotecnol Apl [Internet]. 2006 [cited 2020 Dec 24];23:186-93. Available at: https:// biblat.unam.mx/es/revista/biotecnologia-aplica da/articulo/inmunosenescencia-implicaciones - para-la-inmunoterapia-de-cancer-en-los-adu Itos-mayores. Spanish.

64. Fülöp T, Dupuis G, Witkowski JM, Larbi A. The role of immunosenescence in the development of age-related diseases. Rev Inves Clin. 2016 Mar-Apr;68(2):84-91.

65. Agrawal A, Gupta S. Impact of aging on dendritic cell functions in humans. Ageing Res Rev. 2011 Jul;10(3):336-45.

66. Cunha LL, Perazzio SF, Azzi J, Cravedi P, Riella LV. Remodeling of the immune response with aging: immunosenescence and its potential impact on COVID-19 immune response. Front Immunol. 2020 Aug 7:11:1748. DOI: 10.3389/ fimmu.2020.01748

67. Grubeck-Loebenstein B, Wick G. The aging of the immune system. Adv Immunol. 2002;80:243-84.

68. Pawelec G. Age and immunity: what is "immunosenescence"? Exp Gerontol. 2018 May;105:4-9.

69. Yang JK, Lin SS, Ji XJ, Guo LM. Binding of SARS coronavirus to its receptor damages islets and causes acute diabetes. Acta Diabetol. 2010 Sep;47(3):193-9.

70. van Baarle D, Tsegaye A, Miedema F, Akbar A Significance of senescence for virus-specific memory $\mathrm{T}$ cell responses: rapid ageing during chronic stimulation of the immune system. Immu nol Lett. 2005 Feb 15;97(1):19-29.

71. Franceschi C, Monti D, Sansoni P, Cossarizza A. The immunology of exceptional individuals: the lesson of centenarians. Immunol Today. 1995 Jan;16(1):12-6.

72. Wang B, Li R, Lu Z, Huang Y. Does comorbid ity increase the risk of patients with COVID-19: evidence from meta-analysis. Aging (Albany NY) 2020 Apr 8;12(7):6049-57.

73. Ekiz T, Pazarl AC. Relationship between COV ID-19 and obesity. Diabetes Metab Syndr. 2020 Sep-Oct;14(5):761-3.

74. Muscogiuri G, Pugliese G, Barrea L, Savastano S, Colao A. Comentary: Obesity: The "Achilles heel" for COVID-19? Metabolism. 2020 Jul 1;108:154251. DOI:10.1016/j.metabo .2020 .154251

75. Kumar A, Arora A, Sharma P, Anikhindi SA Bansal N, Singla $V$, et al. Is diabetes mellitus associated with mortality and severity of COVID-19? A meta-analysis. Diabetol Metab Syndr. 2020 Jul-Aug;14(4):535-45.

76. Hu Y, Sun J, Dai Z, Deng H, Li X, Huang Q, et al. Prevalence and severity of corona virus disease 2019 (COVID-19): a systematic review and metaanalysis. J Clin Virol. 2020 Jun;127:104371. DOI: 10.1016/j.jcv.2020.104371

77. EIGohary GM, Hashmi S, Styczynski J, KharfanDabaja MA, Alblooshi RM, de la Cámara R, et al. The risk and prognosis of COVID-19 infection in cancer patients: a systematic review and meta-analysis. Hematol Oncol Stem Cell Ther [Internet]. 2020 Jul 30 [cited 2020 Dec 24]. DOI: 10.1016/j.hemonc.2020.07.005. Online ahead of print. Available at: https://www.ncbi.nlm.nih.gov/ pmc/articles/PMC7390725/

78. Liang W, Guan W, Chen R, Wang W, Li J, Xu K et al. Comment: Cancer patients in SARS-CoV-2 infection: a nationwide analysis in China. Lancet Oncol. 2020 Mar;21(3):335-7.

79. Barbé-Tuana F, Funchal G, Schmitz CRR, Maurmann RM, Bauer ME. The interplay between immunosenescence and age-related diseases. Semin Immunopathol. 2020 Oct:42(5):545-57.

80. Chait A, den Hartigh LJ. Adipose tissue distribution, inflammation and its metabolic consequences, including diabetes and cardiovascular disease. Front Cardiovasc Med. 2020 Feb 25;7:22. DOI: 10.3389/fcvm.2020.00022

81. Burhans MS, Hagman DK, Kuzma JN, Schmidt KA, Kratz M. Contribution of adipose tissue inflammation to the development of type 2 diabetes mellitus. Compr Physiol. 2018 Dec 13;9(1):158.

82. Petrakis D, Margină D, Tsarouhas K, Tekos F, Stan M, Nikitovic D, et al. Obesity - a risk factor for increased COVID-19 prevalence, severity and lethality. Mol Med Rep. 2020 Jul;22(1):9-19.

83. Boutens L, Stienstra R. Adipose tissue macrophages: going off track during obesity. Diabetologia. 2016 May;59(5):879-94

84. Geng S, Chen K, Yuan R, Peng L, Maitra U, Diao $\mathrm{N}$, et al. The persistence of low-grade inflammatory monocytes contributes to aggravated aterosclerosis. Nat Commun. $2016 \mathrm{Nov}$ 8;7:13436. DOI: 10.1038/ncomms13436
85. Laird E, Rhodes J, Kenny RA. Vitamin D and inflammation: potential implications for severity of COVID-19. Ir Med J. 2020 May 7;113(5):81.

86. Li MY, Li L, Zhang Y, Wang XS. Expression of the SARS-CoV-2 cell receptor gene ACE2 in a wide variety of human tissues. Infect Dis Poverty. 2020 Apr 28;9(1):45. DOI: 10.1186/s40249-020 -00662-x

87. Al-Benna S. Association of high level gene expression of ACE2 in adipose tissue with mortality of COVID-19 infection in obese patients. Obes Med. 2020 Sep;19:100283. DOI: 10.1016/j obmed.2020.100283

88. Serra Valdés MA. Las enfermedades crónicas no transmisibles y la pandemia por COVID-19. Rev Finlay [Internet]. 2020 Jun [cited 2020 Dec 25];10(2):78-88. Available at: http://www.rev finlay.sld.cu/index.php/finlay/article/view/846. Spanish.

89. Williams B, Mancia G, Spiering W, Rose EA, Azizi M, Burnier M, et al. 2018 ESC/ESH Guidelines for the management of arterial hypertension: The Task Force for the management of arterial hypertension of the European Society of Cardiology (ESC) and the European Society of Hypertension (ESH). Eur Heart J. 2018 Sep 1;39(33):3021-104.

90. Wenzel U, Turner JE, Krebs C, Kurts C, Harrison DG, Ehmke H. Immune mechanisms in arterial hypertension. J Am Soc Nephrol. 2016 Mar; 27(3):677-86

91. Norlander AE, Madhur MS, Harrison DG. The immunology of hypertension. J Exp Med. 2018 Jan 2:215(1):21-33.

92. Siedlinski M, Jozefczuk E, Xu X, Teumer A, Evangelou $E$, Schnabel RB, et al. White blood cells and blood pressure. A Mendelian randomization study. Circulation. 2020 Apr 21;141(16):1307-17.

93. Rodríguez-Iturbe $B$. The participation of immunity in the pathogenesis of arterial hypertension. Nefrologia. 2020 Jan-Feb;40(1):1-3. English, Spanish.

94. Youn JC, Yu HT, Lim BJ, Koh MJ, Lee J, Chang DY, et al. Immunosenescent CD8+ T Cells and C-X-C chemokine receptor type 3 chemokines are increased in human hypertension. Hypertension. 2013 Jul;62(1):126-33.

95. Virchow R. Cellular pathology. As based upon physiological and pathological histology. Lecture XVI--Atheromatous affection of arteries. 1858. Nutr Rev. 1989 Jan;47(1):23-5.

96. Qu X, Tang Y, Hua S. Immunological approaches towards cancer and inflammation: a cross talk. Front Immunol. 2018 Mar 20;9:563. DOI: 10.3389/fimmu.2018.00563

97. Schetter AJ, Heegaard $\mathrm{NH}$, Harris CC. Inflammation and cancer: interweaving microRNA, free radical, cytokine and p53 pathways. Carcinogenesis. 2010 Jan 1;31(1):37-49.

98. Grivennikov SI, Greten FR, Karin M. Immunity, inflammation, and cancer. Cell. 2010 Mar 19;140(6):883-99.

99. Munn L. Cancer and Inflammation. Wiley Interdiscip Rev Syst Biol Med. 2017 Mar;9(2). DOI: 10.1002/wsbm.1370

100. Aguilar-Cazares D, Chavez-Domínguez R, Carlos-Reyes A, López-Camarillo C, Hernández de la Cruz ON, López-González JS. Contribution of angiogenesis to inflammation and cancer Front Oncol. 2019 Dec 12;9:1399. DOI: 10.3389/ fonc.2019.01399

101. Qian S, Golubnitschaja O, Zhan X. Chronic inflammation: key player and biomarker-set to predict and prevent cancer development and progression based on individualized patient profiles. EPMA J. 2019 Nov 20;10(4):365-81.

102. Jones D, Neal RD, Duffy SRG, Scott SE Whitaker KL, Brain K. Comment. Impact of the COVID-19 pandemic on the symptomatic diagnosis of cancer: the view from primary care. Lancet Oncol. 2020 Jun;21(6):748-50. 
103. Zhang L, Zhu F, Xie L, Wang C, Wang J, Chen R, et al. Clinical characteristics of COVID-19-infected cancer patients: a retrospective case study in three hospitals within Wuhan, China. Ann Oncol. 2020 Jul;31(7):894-901.

104. Ghosh S, Das S, Mondal R, Abdullah S, Sultana $S$, Singh $S$, et al. A review on the effect of COVID-19 in type 2 asthma and its management. Int Immunopharmacol. 2021 Feb:91:107309. DOI: 10.1016/j.intimp.2020.107309

105. Zhao Q, Meng M, Kumar R, Wu Y, Huang J, Lian $\mathrm{N}$, et al. The impact of COPD and smoking history on the severity of COVID-19: a systemic review and meta-analysis. J Med Virol. 2020 Oct;92(10):1915-21.

106. Liu S, Zhi Y, Ying S. COVID-19 and asthma: reflection during the pandemic. Clin Rev Allergy Immunol. 2020 Aug;59(1):78-88.

107. Leung JM, Yang CX, Tam A, Shaipanich T, Hackett TL, Singhera GK, et al. ACE-2 expression in the small airway epithelia of smokers and COPD patients: implications for COVID-19. Eur Respir J. 2020 May 14;55(5):2000688. DOI: $10.1183 / 13993003.00688-2020$

108. Figueira Gonçalves JM, Golpe R, García-Talavera I. Chronic obstructive pulmonary disease and SARS-CoV-2 infection. What do we know so far? Arch Bronconeumol. 2020 Jul;56 Suppl 2:5-6. English, Spanish.

109. Kreutz R, El-Hady Algharably EA, Azizi M, Dobrowolski P, Guzik T, Januszewicz A, et al. Hypertension, the renin-angiotensin system, and the risk of lower respiratory tract infections and lung injury: implications for COVID-19. Cardiovasc Res. 2020 Aug 1;116(10):1688-99.

110. Global Strategy for Asthma Management and Prevention [Internet]. Wisconsin: Global Initiative for Asthma; 2019 Jun [cited 2020 Dec 24]. Chapter 1, Definition, description, and diagnosis of asthma; p. 16. Available at: https://ginasthma .org/wp-content/uploads/2019/06/GINA-2019 -main-report-June-2019-wms.pdf

111. Hosoki K, Chakraborty A, Sur S. Molecular mechanisms and epidemiology of COVID- 19 from an allergist's perspective. J Allergy Clin Immunol. 2020 Aug;146(2):285-99

112. Carrillo T, Martínez JA, Cumplido JA. IgE y asma: El resurgir de una vieja relación. Diferentes tipos de respuesta inflamatoria en el asma. Arch Bronconeumol. 2006;42 Suppl 1:13-9. DOI: 10.1157/13097252. Spanish.

113. García-Pachón E, Zamora-Molina L, SolerSempere MJ, Baeza-Martínez C, Grau- Delgado J, Canto-Reig V, et al. Asthma prevalence in patients with SARS-CoV-2 infection detected by RT-PCR not requiring hospitalization. Respir Med. 2020 Sep;171:106084. DOI: 10.1016/j.rmed .2020 .106084

114. Grandbastien M, Piotin A, Godet J, AbessoloAmougou I, Ederlé C, Enache I, et al. SARS-CoV-2 pneumonia in hospitalized asthmatic patients did not induce severe exacerbation. J Allergy Clin Immunol Pract. 2020 Sep;8(8):2600-7.

115. Chhiba KD, Patel GB, Vu THT, Chen MM, Guo A, Kudlaty $E$, et al. Prevalence and characterization of asthma in hospitalized and nonhospitalized patients with COVID-19. J Allergy Clin Immunol. 2020 Aug;146(2):307-14.e4.

116. Skevaki C, Karsonova A, Karaulov A, Xie M, Renz H. Asthma-associated risk for COVID-19 development. J Allergy Clin Immunol. 2020 Dec;146(6):1295-301.

117. Abrams EM, 't Jong GW, Yang CL. Asthma and COVID-19. CMAJ. 2020 May 19;192(20):E551.

118. Carli G, Cecchi L, Stebbing J, Parronchi P, Farsi A. Is asthma protective against C COVID-19? Allergy. 2020 Jun 17;00:1-3. DOI: 10.1111/ all.14426

119. Holgate ST, Wenzel S, Postma DS, Weiss ST, Renz H, Sly PD. Asthma. Nat Rev Dis Primers. 2015;1(1):15025. DOI:10.1038/nrdp.2015.25

120. Mendes NF, Jara CP, Mansour E, Araújo EP, VelIoso LA. Asthma and COVID-19: a systematic review. Allergy Asthma Clin Immunol. 2021 Jan $6 ; 17(1): 5$

121. Calvielli AC, Notomi M, Wesley R. Branco ACCC, Sato MN, Alberca RW. The possible dual role of the ACE2 receptor in asthma and Coronavirus
(SARS-CoV2) infection. Front Cell Infect Microbiol. 2020 Sep 23;10:550571. DOI: 10.3389/ fcimb.2020.550571

122. Hughes-Visentin A, Mahesan Paul AB. Asthma and COVID-19: what do we know now. Clin Med Insights Circ Respir Pulm Med. 2020 Oct 23;14:1179548420966242.

123. Öztürk $A B$, Cağlayan $B$. Angiotensin converting enzyme-2 (ACE2) receptors, asthma and severe COVID-19 infection risk. Eur Ann Allergy Clin Immunol. 2020 Nov;52(6):282-5.

124. Morais-Almeida M, Pité H, Aguiar R, Ansotegui I, Bousquet J. Asthma and the Coronavirus disease 2019 pandemic: a literature review. Int Arch Allergy Immunol. 2020;181(9):680-8.

\section{THE AUTHORS}

Anamary Suárez-Reyes (Corresponding author: anamarysuarez.89@gmail.com), physician with dual specialties in family medicine and immunology. Instructor at the Medical University of Havana (UCMH); Immunology Laboratory, National Oncology and Radiobiology Institute (INOR), Havana, Cuba. https://orcid.org/0000 -0003-0289-0230

Carlos Agustín Villegas-Valverde, physician with dual specialties in family medicine and immunology, and master's degrees in infectious diseases and medical education. Associate professor and associate researcher, (UCMH); Immunology Laboratory, INOR, Havana, Cuba. https://orcid.org/0000-0001-7478-0482

Submitted: October 2, 2020

Approved for Publication: April 5, 2021

Disclosures: None 